\title{
Chilean wildfires: probabilistic prediction, emergency response and public communication
}

Article

Published Version

Open Access

Dacre, H. F., Crawford, B. R., Charlton-Perez, A. J., LopezSaldana, G., Griffiths, G. H. and Vicencio Veloso, J. (2018) Chilean wildfires: probabilistic prediction, emergency response and public communication. Bulletin of the American Meteorological Society. pp. 2259-2274. ISSN 1520-0477 doi: https://doi.org/10.1175/BAMS-D-17-0111.1 Available at https://centaur.reading.ac.uk/77659/

It is advisable to refer to the publisher's version if you intend to cite from the work. See Guidance on citing.

To link to this article DOI: http://dx.doi.org/10.1175/BAMS-D-17-0111.1

Publisher: American Meteorological Society

All outputs in CentAUR are protected by Intellectual Property Rights law, including copyright law. Copyright and IPR is retained by the creators or other copyright holders. Terms and conditions for use of this material are defined in the End User Agreement. 


\section{CentAUR}

Central Archive at the University of Reading

Reading's research outputs online 


\title{
CHILEAN WILDFIRES Probabilistic Prediction, Emergency Response, and Public Communication
}

\author{
H. F. Dacre, B. R. Crawford, A. J. Charlton-Perez, \\ G. Lopez-Saldana, G. H. Griffiths, and J. Vicencio Veloso
}

This paper details the design, development, and initial testing of a prototype probabilistic wildfire warning system for Chile.

W ildfires are fires that spread unchecked in forest/rural lands and rural-urban interfaces, through forests, woody shrubs, and herbaceous vegetation, living or dead (Ubeda and Sarricolea 2016). They can burn from days to weeks and can lead to loss of life and property. Given the enormous damage potential, a number of warning systems have been developed to forecast wildfire occurrence and severity on a variety of temporal scales. At decadal time scales, wildfire forecasts made using predicted

affiliations: Dacre, Crawford,* Charlton-PerezDepartment of Meteorology, University of Reading, Reading, United Kingdom; LopEz-SALDANA-Assimila, Ltd., Reading, United Kingdom; GRIFFITHS-Institute for Environmental Analytics, Reading, United Kingdom; VICENCIO Veloso-Dirección Meteorologica de Chile, Santiago, Chile

*ADDITIONAL AFFILIATIONS: Crawford-Department of Civil and Environmental Engineering, Massachusetts Institute of Technology, Cambridge, Massachusetts CORRESPONDING AUTHOR: H. F. Dacre,

h.f.dacre@reading.ac.uk

The abstract for this article can be found in this issue, following the table of contents.

DOI:10.II75/BAMS-D-17-01II.I

In final form 24 April 2018

C2018 American Meteorological Society

For information regarding reuse of this content and general copyright information, consult the AMS Copyright Policy. climate change scenarios indicate that the number of wildfires will increase in the future (Running 2006). Seasonal forecasts, based on relationships between the previous season's atmospheric conditions and the subsequent season's wildfire occurrence and burned area extent can be used for long-range planning of allocation of resources (Westerling et al. 2003; Chu et al. 2002). At shorter time scales, daily forecasts can be used to alert the public and first responders and to manage the deployment of fire crews and equipment. Such early warning systems are essential components of fire suppression planning. In this paper, we focus on the design of a daily wildfire warning system for Chile, a country severely affected by wildfires in the recent 2016/17 wildfire season.

The complexity of wildfire models varies, but most consist of regionally calibrated statistical relationships built using historical information about vegetation moisture (either estimates made using fuel models or based on drought estimations, or both), atmospheric data (either surface station data or numerical weather prediction analysis), and wildfire data (using groundbased or Earth observation measurements). The degree to which wildfire models rely on Earth observation data (i.e., satellite-based measurements) varies from model to model. The advantages of using Earth observation data are that it allows historical fire and vegetation data to be monitored over large regions and with an accuracy that cannot be matched by ground- 
based methods. However, in countries such as Chile, where fire is used as a land management tool, it is often difficult to discriminate between managed fires and wildfires using fire occurrence observations only. This discrimination is important because the frequency of managed fires is unlikely to depend on the meteorological conditions, unlike wildfires. Of course, this does not mean that managed fires cannot get out of hand in meteorological conditions conducive to their rapid spread.

Wildfire models are used to forecast future occurrence and severity of wildfires in a given location using forecast atmospheric data and vegetation moisture. Commonly used early warning wildfire forecasts systems such as the McArthur Forest Fire Danger Index (FFDI) (Dowdy et al. 2009), the Canadian Fire Weather Index (FWI), and the U.S. National Fire Danger Ratings Systems are examples of early warning systems that attempt to represent hazard levels as a single value (Neale and Weir 2015). Wildfire prediction is however inherently probabilistic. This is because, even if we had perfect knowledge of the physical processes, the state of the atmosphere is not precisely known and cannot be perfectly forecast even on short time scales. Similarly, vegetation characteristics can vary widely across regions and cannot be precisely represented in models. It is therefore necessary to quantify uncertainties in wildfire predictions, which are crucial for making decisions about resource allocation (Taylor et al. 2013). The novelty of this paper is to use a probabilistic approach to predict wildfires.

The synoptic conditions that are likely to produce severe wildfires in Chile are generally well characterized, but the ability of numerical weather prediction models to forecast these conditions depends largely on the evolution of atmospheric pressure systems. Medium-range forecasts (3-7 days) contain greater uncertainty than short-range forecasts (1-3 days) and therefore bring about less confidence in the fire severity forecasts at these time scales. Even so, medium-range forecasts are useful in fire management in that the forecasts can be used in developing resource allocation options but not implementing them until the forecasts are more certain. Probabilistic forecasts provide information on the uncertainty of a forecast. When combined with severity, probabilistic forecasts allow decision-makers to quantitatively assess the risk of severe wildfire events occurring in the days ahead (Masato et al. 2015) and to make decisions accordingly. In this paper, risk is the product of the likelihood of occurrence and the severity of the predicted event. We represent the uncertainty in the meteorological forecast variables by using forecasts from a meteorological ensemble system allowing us to predict the likelihood of severe fires up to six days ahead. The severity of the event is measured either by the total number, intensity (fire radiative power), or area burned by the predicted wildfires.

The aim of the paper is to describe the design and development of a prototype probabilistic wildfire warning system. The paper covers all aspects of the design including the technicalities of building the models, collaboration between U.K. and Chilean meteorologists and wildfire managers, and communication of the warnings. A schematic of the steps involved in designing the probabilistic wildfire warning system is shown in Fig. 1. In step 1, the probabilistic wildfire models are built using historical satellite and weather forecast data. In step 2, the wildfire forecasts are produced using ensemble weather forecast data as input to the wildfire models. Finally, in step 3, the wildfire warnings are communicated on a variety of levels depending on the needs of the end user. This communication system ranges from a fully probabilistic forecast to support the local fire management decision support system to a simple four-category color-coded alert more suitable for the general public.

The paper is structured as follows: the second section describes the datasets used in the paper, the third section describes Chilean land surface and climate characteristics and their relation to wildfire occurrence, the fourth section details the method used to build the probabilistic wildfire model, the fifth section provides an overview of the 2016/17 wildfire season and wildfire forecasts, the sixth section describes the communication of wildfire forecasts, and the seventh section contains a discussion and suggests areas for future work.

DATA. Ensemble meteorological forecast data. The ensemble weather forecast data, for the period from December 2016 to February 2017, are from the National Centers for Environmental Prediction (NCEP) obtained from The Observing System Research and Predictability Experiment (THORPEX) Interactive Grand Global Ensemble (TIGGE) archive hosted by the European Centre for Medium-Range Weather Forecasts (ECMWF; Bougeault et al. 2010). The NCEP forecast data are used because this is what the Dirección Meteorológica de Chile (DMC) uses for their ensemble forecasts. Forecast data are at $0.5^{\circ}$ grid resolution and are issued every $6 \mathrm{~h}$. For model development, we use the historical ensemble control run analysis for 0600 UTC (0200 local Chile time, chosen as the daily forecast closest to 0000 local time) for 
each December-February (DJF) day between January 2011 and February 2016 and assume this is reality.

The meteorological variables of interest are daily total precipitation, 2 -m air temperature, 2 -m relative humidity (calculated from dewpoint temperature), and $10-\mathrm{m}$ wind speed (vector average of $u$ and $v$ components). For each day, the maximum 2-m temperature, minimum relative humidity $(\mathrm{RH})$, maximum wind speed, and total precipitation for each grid cell is determined.

Vegetation state from Earth observation data. Vegetation-state monitoring at continental scale can be achieved using a time series of vegetation indices

\section{1: \\ Build Wildfire Models}

2:

Produce

Wildfire

Forecasts
3:

Communicate

Wildfire

Warnings
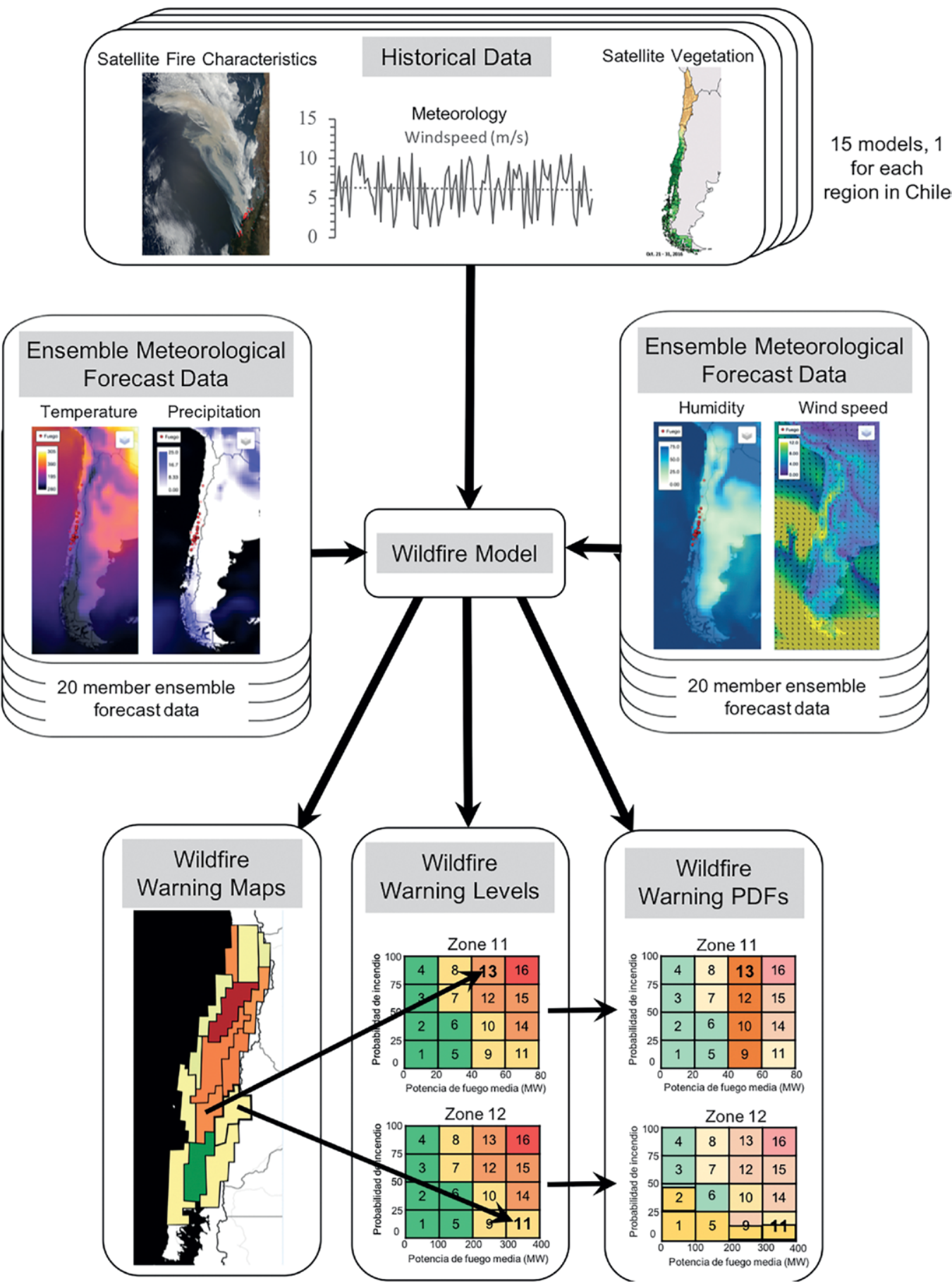

FIG. I. The three-step process for building and disseminating warnings from a probabilistic wildfire warning system. 
derived from multispectral Earth observation (EO) data. One of the most widely used is the normalized difference vegetation index (NDVI; Tucker 1979). NDVI is computed as a normalized difference of the red and infrared light reflected by vegetation. Green photosynthetically active vegetation absorbs most of the visible light and reflects a large proportion of the incident near-infrared. Values range from -1.0 to 1.0; water exhibits negative NDVI values; burned areas, bare soil, sand, or snow usually produce very low NDVI values (for instance, 0.1 or less), while healthy forests show high NDVI values (typically greater than 0.6). Therefore, the NDVI can be used to establish when there is fuel available for a fire to ignite and spread.

To capture the vegetation fuel availability over time, the MCD43C2 datase ${ }^{1}$ is downloaded from the Land Processes Distributed Active Archive Center (LP DAAC). The MCD43C2 products provide the BRDF parameters for different spectral bands at $0.05^{\circ}$ to compute land surface albedo at a common solar viewing geometry every 16 days with an 8 -day overlay providing 46 observations every year. A weighted mean is computed for every 16-day time period using 15 years of data (2002-16); the weights are calculated using the quality flags in the MCD43C3. Using the weighted mean for the red $(620-670 \mathrm{~nm})$ and the near-infrared (841-876 nm), the NDVI climatology is computed.

Satellite fire characteristics data. Active fire information is obtained from the Moderate Resolution Imaging Spectroradiometer (MODIS) collection 6 global monthly fire location product (MCD14ML; Giglio et al. 2016). The fire identification is based on the detection of a fire within a 1-km pixel when the fire strength (in terms of brightness temperature) is strong enough to be detected relative to its background. The monthly fire location product contains the location of each fire, the date, and additional information such as the detection confidence and the amount of energy released in terms of fire radiative power (FRP; in $\mathrm{MW}$ ). Locations and attributes for all fires identified by MODIS Aqua are extracted and regridded to $0.05^{\circ}$.

Burned areas affected by fire each year are derived using the MODIS collection 5.1 direct broadcast monthly burned area product (MCD64A1; Giglio et al. 2009). In addition, for the model evaluation,

\footnotetext{
${ }^{1}$ Bidirectional reflectance distribution function (BRDF)-albedo snow-free quality 16 -day L3 global $0.05^{\circ}$ CMG (MCD43C2) collection 5 .
}

collection 6 became available, and it is used as reference data. The product identifies areas affected by fire using a synergistic approach by associating an abrupt change in surface reflectance and 1-km MODIS active fires. The MCD64A1 spatial resolution is $500 \mathrm{~m}$ and provides the approximate day of burn within a calendar month. It is necessary to aggregate the data to $0.05^{\circ}$ to match the resolution of the MODIS land-cover data described in the "Ancillary datasets" section. The proportion of the $0.05^{\circ}$ grid cell that was burned is kept and the approximate day of burning; where more than one day was identified, the value assigned is the date where the majority of pixels within the grid cell were burned.

As part of the model evaluation, an independent fire dataset is required. We use the Visible Infrared Imaging Radiometer Suite (VIIRS) 375-m active fire product (Schroeder et al. 2014). The VIIRS sensor is on board the National Aeronautics and Space Administration-National Oceanic and Atmospheric Administration (NASA-NOAA) Suomi National Polar-Orbiting Partnership (Suomi NPP) satellite. The VIIRS 375-m active fire data complement the MODIS fire detection since they have an improved spatial and spectral resolution and higher sensitivity to small fires and higher fire detection rates compared to MODIS $500 \mathrm{~m}$ (Oliva and Schroeder 2015).

Ancillary datasets. Population density data are acquired from the History Database of the Global Environment (HYDE), version 3.2 (Klein Goldewijk et al. 2017), and regridded for 2016 to match the TIGGE $0.5^{\circ}$ resolution from the original 5-arc-min HYDE resolution. Population is represented in HYDE as maps of urban population, rural population, population density, and built-up area.

The MODIS collection 5.1 land-cover-type yearly level 3 (L3) global $0.05^{\circ}$ climate modeling grid (CMG; MCD12C1; Friedl et al. 2010) is produced at $0.05^{\circ}$ spatial resolution and provides the dominant land-cover type and the subgrid frequency land-cover class distribution within each cell. The land-cover data are used as part of the visualization tool ("Discussion" section), and in order to show major biomes in Chile, the data were aggregated. We decided that six major vegetation classes were enough to convey the main message but not overwhelm the participants at the workshop (see "Chilean workshop" section), who were not experts in land-cover classifications. The following aggregation is performed from the International Geosphere-Biosphere Programme (IGBP) classes in the MODIS data: 1) the forest classes (deciduous needleleaf, deciduous broadleaf, 
evergreen needleleaf, evergreen broadleaf, and mixed forests) are aggregated into a single "forest" class; 2) croplands and a cropland-natural vegetation mosaic are aggregated into the "agriculture" class; 3 ) closed shrublands and open shrublands into the "shrublands" class; 4) woody savannas and savannas into the "savanna" class; 5) grasslands stay as "grassland"; and 6) permanent wetland, urban and built-up, snow and ice, and barren or sparsely vegetated areas are aggregated to "other."

\section{CHILEAN CLIMATE AND WILDFIRE} CLIMATOLOGY. Chile is in southern South America, bordering the South Pacific Ocean (Fig. 2). It has a population of over 17 million people, with the vast majority living in central Chile, between $42^{\circ}$ and $32^{\circ} \mathrm{S}$. The most density populated region is the capital Santiago (Fig. 2b). The climate in Chile is extremely varied owing to its very large meridional extent. There is a desert climate in northern Chile, a Mediterranean climate in central Chile, and a temperate climate in southern Chile. In central Chile, the warmest temperatures occur in January and February, with maximum 2-m air temperatures on average reaching $28^{\circ} \mathrm{C}$ in the central valley and slightly cooler temperatures $\left(20^{\circ}-24^{\circ} \mathrm{C}\right)$ along the coastal range to the west and the Andes to the east (Fig. 2d). The amount of rainfall increases from north to south in central Chile with summer mean daily total precipitation of $<1 \mathrm{~mm} \mathrm{day}^{-1}$ in Santiago and $>5 \mathrm{~mm} \mathrm{day}^{-1}$ poleward of $40^{\circ} \mathrm{S}$ (Fig. 2f). Chile's principal agricultural region is in central Chile owing to the Mediterranean climate.

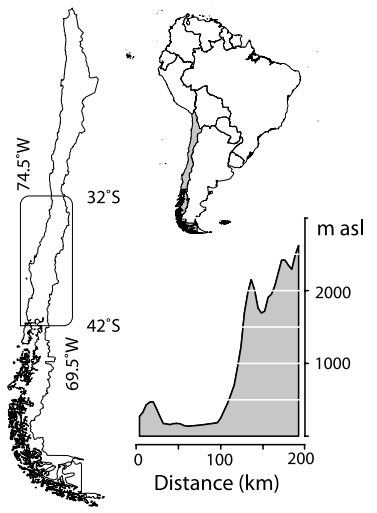

d) 2011-2016 Jan to Feb mean daily maximum $2 \mathrm{~m}$ air temperature

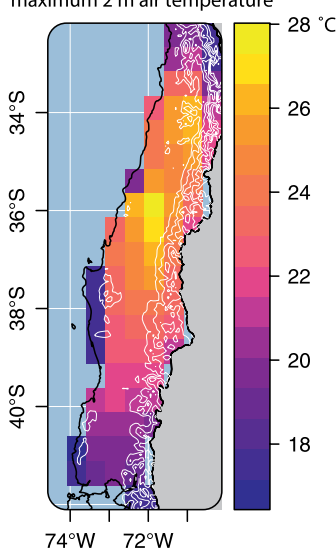

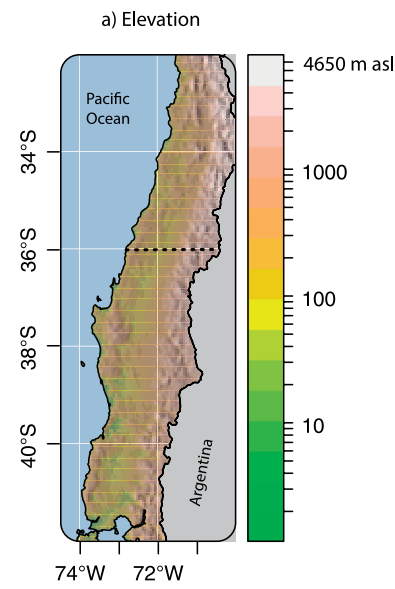

e) Jan 20-31, 2017 mean daily max. $2 \mathrm{~m}$ air temperature anomaly

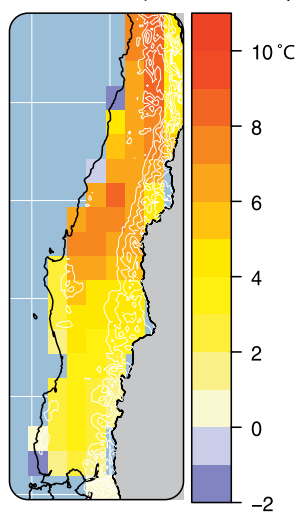

b) Population density (2016)

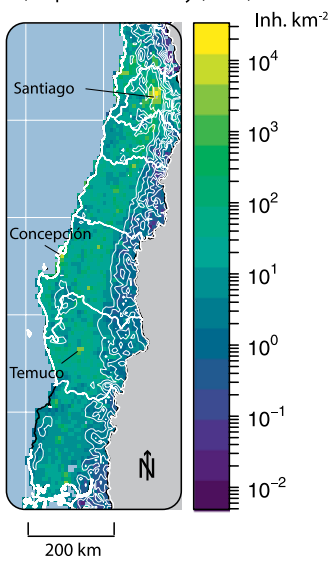

2011-2016 Jan to Feb mean daily total precipitation

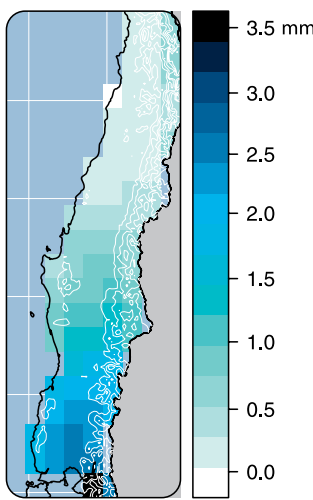

c) Dominant land cover (2012)

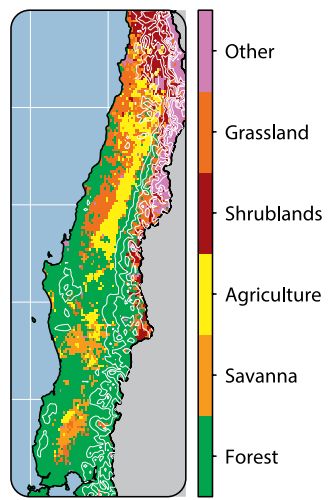

g) Jan 20-31, 2017 mean daily precipitation anomaly

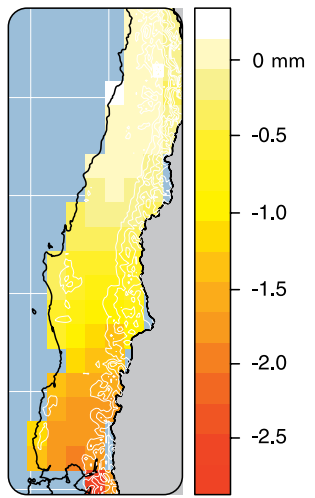

Fig. 2. (a) Elevation $\left(0.05^{\circ}\right.$ resolution), (b) population density $\left(0.05^{\circ}\right.$ resolution; HYDE, version 3.2 .0 , database), (c) dominant land cover ( $0.05^{\circ}$ resolution; MODIS), (d) Jan-Feb 20II-16 mean daily maximum 2-m air temperature [0.5 $5^{\circ}$ resolution; NCEP Experimental Warning Program (EWP) control run, day-0 forecast], (e) air temperature anomaly for 20-3I Jan 2017 (0.5 resolution; NCEP EWP ensemble mean, day-0 forecast), (f) Jan-Feb $201 \mathrm{I}-2016$ mean total precipitation ( $0.5^{\circ}$ resolution; NCEP EWP control run, day-0 forecast), and (g) precipitation anomaly for 20-31 Jan 2017 (0.5 resolution; NCEP EWP ensemble mean, day-0 forecast). The 20-3I Jan period is highlighted to represent the peak of the 2016/17 fire season. Data sources are described in the "Data" section. 
Many of Chile's famous vineyards are located here. Forestry is also one of the main economic sectors of Chile and takes place mainly along the coastal range and in the foothills of the Andes with agriculture predominantly in the central valley (Fig. 2c).

Wildfires are common in climates that are sufficiently moist to allow the growth of vegetation but feature extended dry, hot periods such as found in central Chile (Holz et al. 2012; Ubeda and Sarricolea 2016; González et al. 2005). A 14-yr climatology of wildfires in Chile is been compiled from MODIS Aqua satellite data described in the "Satellite fire characteristics data" section. The largest number of fires are observed in zone 11 near Temuco, Chile (Fig. 3a). This region is predominantly savanna (Fig. 2c) and is subject to regular managed fires used to control the growth of tree seedlings, thus preventing the establishment of a continuous tree canopy, which acts to prevent grass growth. The open structure of savannas are commonly used for grazing domestic livestock. This extensive burning results in a high annual-mean burned area of up to $30 \%$ (Fig. 3c). A high number of fires is also seen in a band extending from Temuco along the central valley up to Santiago; this is predominantly agricultural land. The majority of these fires in the central valley region are managed and are of low intensity (Fig. 3b). In these regions, therefore, the total number of fires is unlikely to depend strongly on the large-scale meteorological conditions (Holz et al. 2012).

There are also a high number of fires detected on the western side of the coastal range (Fig. 3a). This region is predominantly covered by forest. Fires are often of high intensity, resulting in localized burned areas of up to $10 \%$ (Fig. 3c). Many of these very intense fires occur close to highly populated areas. Since these forest fires are not intentionally lit, it is likely that their intensity will depend on the large-scale meteorological conditions. We therefore hypothesize that a wildfire model predicting fire radiative power (intensity) will be more skillful than wildfire models predicting fire occurrence or burned area since these metrics are more likely to be dominated by managed fires. This will be tested in the "Communicating wildfire forecasts: Step 3" section for the 2016/17 wildfire season.

The 20/6/17 synoptic situation. The 2016/17 wildfire season (defined here as DJF 2016/17) recorded the largest frequency of wildfires in Chilean history, particularly during the latter half of January 2017. In general, conditions in central Chile during this period were characterized by extremely high temperatures, above-average wind speeds, and virtually no precipitation (Fig. 2g).
Synoptically, January 2017 was dominated by a strong ridge over Chile, especially between $20^{\circ}$ and $40^{\circ} \mathrm{S}$. This situation produced stable conditions over central Chile and enhanced subsidence. NCEPNational Center for Atmospheric Research (NCAR) reanalysis data show positive geopotential height anomalies in the mid- and upper troposphere in this area, with a maximum anomaly located offshore from the central Chile coast $\left(30^{\circ}-36^{\circ} \mathrm{S}\right)$. On average, the monthly average anomaly was between 70 and $80 \mathrm{~m}$ at $500 \mathrm{hPa}$ (not shown). The location of the minimum sea level pressure anomaly (between -1 and $-2 \mathrm{hPa}$, near $30^{\circ}-31^{\circ} \mathrm{S}, 75^{\circ} \mathrm{W}$ ) was important for January's wildfire outbreak as well. In the southern part of the low pressure anomaly, offshore winds were up to $3 \mathrm{~m} \mathrm{~s}^{-1}$ above average. The coastal low also generated katabatic winds west of the Andes, providing additional warming to both the coast and central valley regions of Chile.

During the second part of January, the anomalous pattern was strongest, with a coastal low located offshore at $30^{\circ} \mathrm{S}$. This contributed to warmer-thannormal conditions between $32^{\circ}$ and $36^{\circ} \mathrm{S}$, with strong winds and clear skies for several days. Between 18 and 25 January, the pattern remained stagnant, and most of the biggest forest fires of the season were initiated at this latitude. Between 26 and 28 January, the low pressure system moved southward because of a slow midtroposphere movement to the east of the ridge. The low pressure system produced stronger winds offshore in southern central Chile $\left(33^{\circ}-36^{\circ} \mathrm{S}\right)$ and generated katabatic winds, coinciding with record high temperature in Santiago, Curicó, Chillán, and Los Ángeles, Chile. The most intense wildfires were also displaced to these regions.

Based on NCEP gridded forecasts, daily maximum 2-m air temperatures from 20 to 31 January 2017 in central Chile were up to $9^{\circ} \mathrm{C}$ higher than the January-February average from 2011 to 2016 (Fig. 2e). This time period is used to illustrate the extreme temperature and precipitation conditions during this period even in comparison to recent drought conditions affecting central Chile since 2010 (Aldunce et al. 2017). During this period, there was also virtually no precipitation in central Chile where fire outbreaks were most severe (Fig. 2g). During the DJF fire season, there was a total precipitation deficit of $-2600 \mathrm{~mm}$ for the entire central Chile region (76 $0.5^{\circ}$ grid cells) relative to 2011-16 DJF totals.

\section{BUILDING THE PROBABILISTIC WILDFIRE MODEL: STEP I. The probabilistic wildfire} model developed for this work is based on statistical 
relations between three sources of data described in the "Data" section: i) historical weather forecasts, ii) historical normalized difference vegetation index (NDVI), and iii) historical satellite-observed wildfire characteristics.

The model uses six years (2008-13) of daily meteorological, NDVI, and fire data and predicts three characteristics of wildfires: i) number of fires, ii) average intensity of each fire (MW), and iii) total burned area (BA; in ha). Currently, there are specific predictions for 15 geographic regions in central Chile.

The model is generally based on an earlier wildfire severity index model developed for Chile by Julio (1990). This model introduces 15 unique geographic wildfire zones that loosely distinguish between vegetation types in central Chile (Fig. 1, step 3). These zones are somewhat arbitrary, and their delineation is likely outdated (e.g., from land-use and land-cover changes); however, the zones remain adequate for the purposes of demonstrating the feasibility of this approach. All gridded meteorological forecasts, fire observations, and NDVI data are aggregated to these geographic zones for model development.

Model development. Model coefficients are determined for each zone for the three wildfire metrics (total count, mean FRP, and BA) using six years of daily meteorological and wildfire data and daily average NDVI. For mean FRP and BA, we use a multiple linear regression model. For the fire count, a negative binomial regression model is used to give nonnegative predictions and account for discrete fire count data. This approach is based on the Julio (1990) model, and we elected to stay with this technique to maintain continuity and comparability within the DMC forecasting framework and because of its relatively straightforward implementation. During model development, we use DecemberFebruary data to avoid agricultural fires that occur primarily from March to May and are presumed to be less dependent on meteorological conditions.

As model predictors, we use the daily maximum 2-m air temperature, minimum $\mathrm{RH}$, maximum wind speed, and total 24 -h precipitation for each a) Total number of fires (2001-2015)
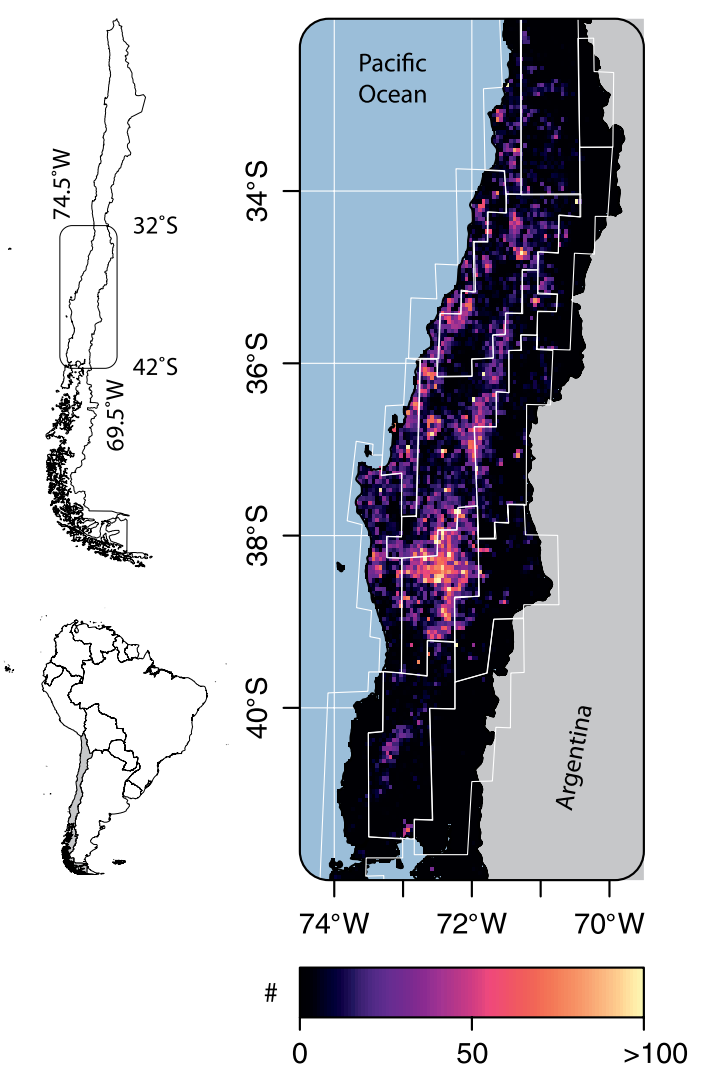

b) Mean fire radiative power (2001-2015)
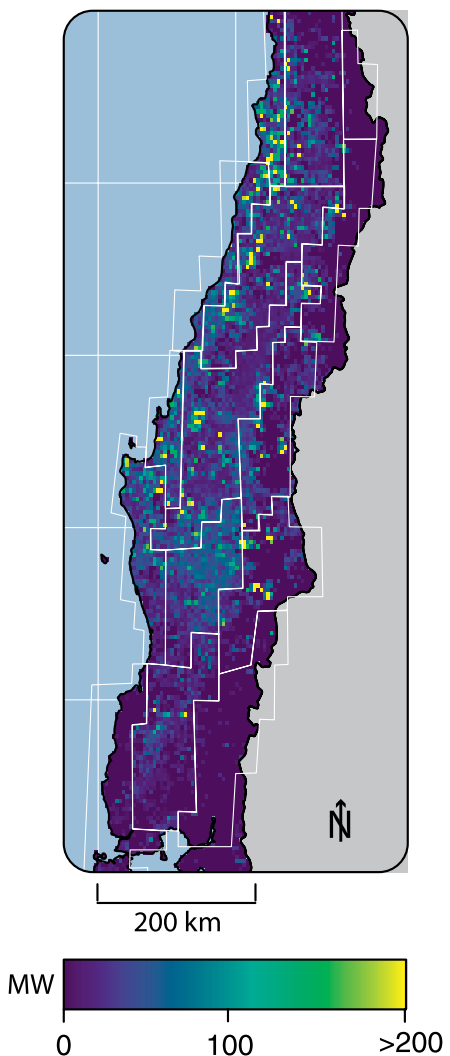

c) Annual mean burned area (2002-2014)

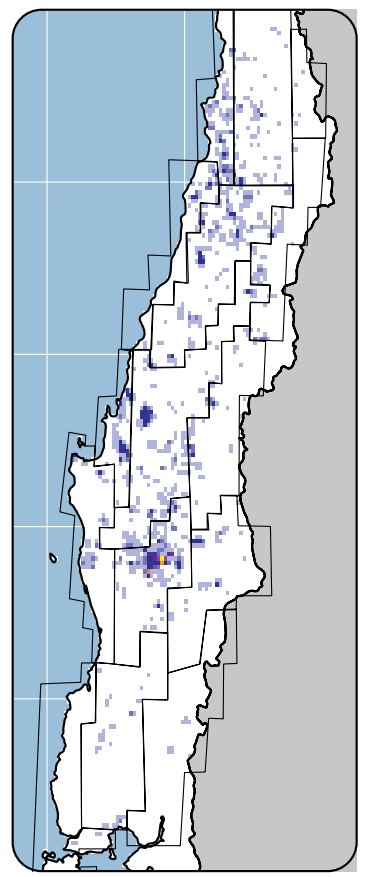

$\%$

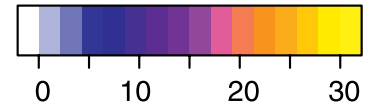

Fig. 3. (a) Total number of fires from 2001 to 2015 , (b) mean FRP (MW) for all fires during 200I-I5, (c) mean annual BA (percentage of each pixel) from 2002 to 2014 . Data are aggregated to $0.05^{\circ}$ resolution from MODIS Aqua satellite (see "Data" section). 
zone. These variables are selected based on previous statistical relations with wildfire risk determined for specific geographic zones in Chile (Julio 1990). Air temperature and $\mathrm{RH}$ are associated with fuel drying rates, precipitation with fuel moisture content, and wind speed with drying and potential for fire propagation. Variations of these variables are also used globally as input to the Canadian FWI, a fire-danger rating system widely used throughout the world (Field et al. 2015). The Canadian FWI, which differs slightly from our model, uses 2-m air temperature, relative humidity, $10-\mathrm{m}$ wind speed, and $24-\mathrm{h}$ precipitation total ending at 1200 local time.

In addition, because wildfires can consume heavy surface and deep soil fuels that dry on time scales longer than a single day (e.g., Van Wagner et al. 1987), we also use a degree-day approach to account for antecedent weather conditions. Degree-days are commonly used in a variety of applications such as predicting energy demand (e.g., heating degree-days) or vegetation growing season length (growing degreedays). For this study, fire degree-days (FDD) are calculated using a baseline temperature $T_{B}$ of $16.5^{\circ} \mathrm{C}$. This $T_{B}$ resulted in lowest mean absolute error (MAE) relative to observations in zone 8 (zone with highest occurrence of fires) and is applied to all zones. When daily $T_{\max }<T_{B}, F D D=0$, and accumulated FDD for $n$ number of days is defined as

$$
\mathrm{FDD}=\sum_{i=l}^{i-n}\left(T_{\max , i}-T_{B}\right) .
$$

In addition to daily meteorological values, rolling sums of accumulated FDD and total precipitation are used to incorporate weather conditions during preceding days into the model. Based on repeated iteration, two separate accumulation times (for both precipitation and temperature) of 45 and 12 days are found to result in lowest model MAE relative to observations. These periods are similar to those found in other models such as the Canadian FWI (Van Wagner et al. 1987) and the Global Fire Weather Database (Field et al. 2015), and their physical interpretation is related to drying rates of duff (midlevel organic layer) and deeper-soil fuel levels.

Additionally, fire counts are found to vary depending on day of week, suggesting an anthropogenic influence to wildfire occurrence (though this is not included as a predictor variable in the current model). In summary, there are nine input predictor variables to the model (five daily values and four accumulated values) and three predicted outputs (fire count, mean FRP, and BA; Table 1).

\section{THE 2016/17 WILDFIRE FORECASTS: STEP 2.}

Wildfire metrics are predicted for the December 2016February 2017 fire season for each zone. For each day during the case study, the forecast issue at 0600 UTC is used, and wildfire metrics are forecast up to 6 days in advance based on daily predicted meteorological values (Table 1). The 12- and 45-day accumulated FDD and precipitation are also calculated based on predictions through the 6-day forecast period.

For each day, there are 20 individual ensemble members for each meteorological variable. Model coefficients are applied to each ensemble member, resulting in 20 individual predictions for each wildfire metric for each zone. These 20 members are then used to develop probability distributions for each wildfire metric in each zone.

The daily model forecasts are compared to observations from two independent sources: MODIS and VIIRS satellites ("Satellite fire characteristics data" section). The 2016/17 MODIS data were withheld from model training, and the VIIRS dataset is completely independent of the model. The 3-day forecast is used as reference, and modeled and observed wildfire characteristics are aggregated across all 15 zones for this comparison (Fig. 4).

The 2016/17 fire season began quietly through December and early January. Although December daily maximum air temperatures were above average $\left(6^{\circ} \mathrm{C}\right.$ above the 2008-13 model-training-period average), precipitation helped keep wildfire outbreaks relatively mild (Fig. 4d). Overall, VIIRS and MODIS satellites observe very similar temporal patterns of wildfire activity; however, 
VIIRS records higher magnitude of wildfire occurrence because of higher spatial resolution ("Satellite fire characteristics data" section). In December, MODIS (VIIRS) observed daily wildfire occurrence ranged from 0 to 174 (4-768) fires with mean daily FRP of 47.8 (51.5) MW.

On 6 January, the observed intensity (FRP) of wildfires began to increase even though wildfire
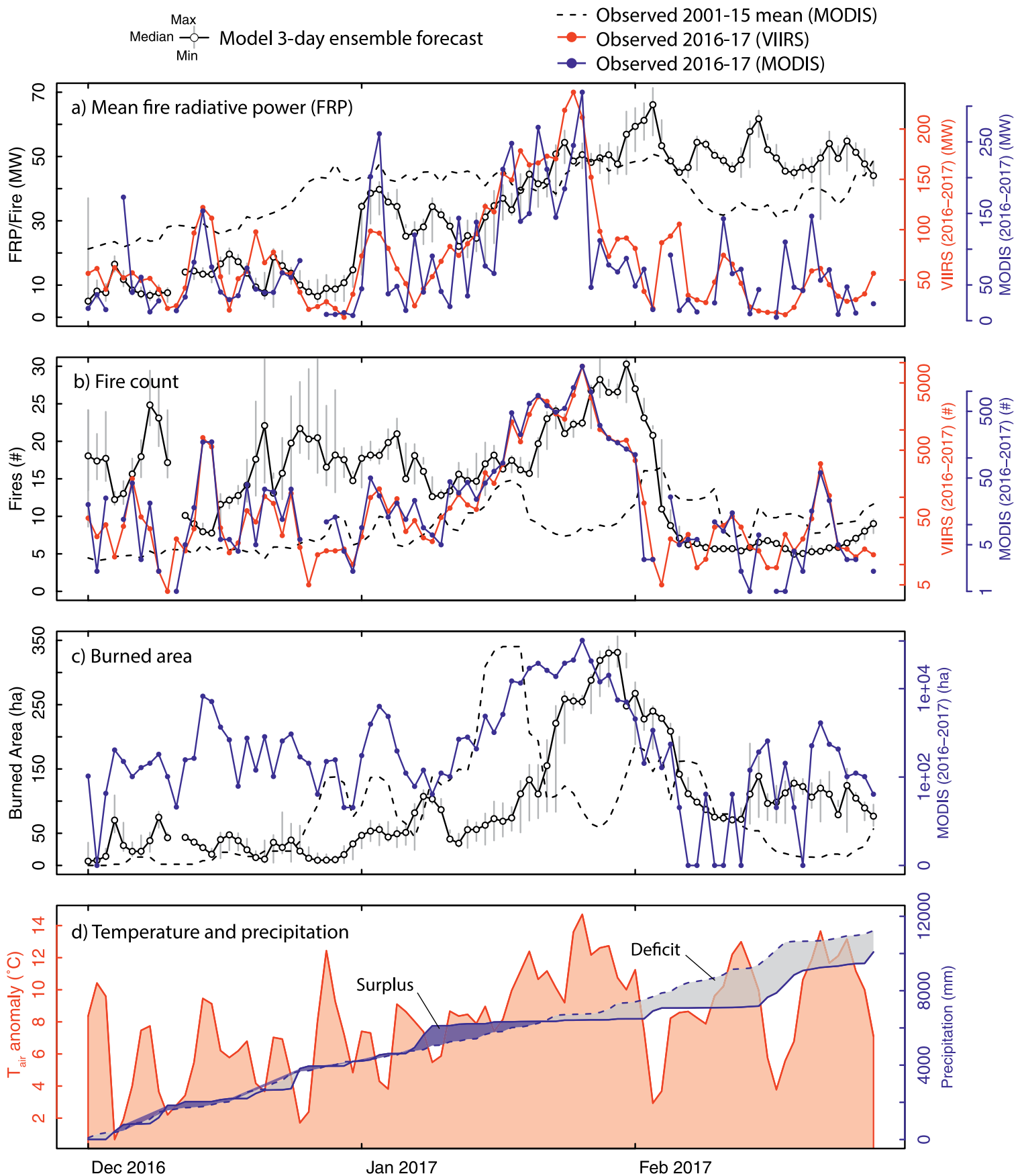

Fig. 4. Observed and modeled daily (a) mean wildfire radiative power (MW), (b) wildfire count , (c) burned area (ha), and (d) air temperature anomaly and total precipitation (relative to 2008-13 model training period). For all panels, data are aggregated for all 15 wildfire zones in central Chile. Ensemble model daily maximum and minimums are shown as vertical gray bars. In (a)-(c), MODIS-observed daily means from 2001 to 2015 (dashed line) are shown for comparison using a 10-day running mean. MODIS and VIIRS 2016/17 observations (blue and red) are shown using different $y$-axis scales. The observed 2016/17 wildfire occurrence in (b) y-axis scale is logarithmic. In (d), air temperature anomaly and precipitation deficits and surplus are relative to $2008-13$ averages. 
occurrence remained relatively low. Then on 18 January, the number of observed wildfires rapidly increased with a MODIS-observed day-today increase from 84 to 475 fires (310-1,316 VIIRS). Peak activity occurred on 26 January, with 2,368 MODIS-observed wildfires (8,827 VIIRS), an order of magnitude larger than recorded in recent history (2008-15). Peak observed burned area occurred on 26 January $(123,829$ ha). Wildfire activity quickly dropped off from 27 January to 5 February, though fires continued to burn well into February.

In general, the wildfire models predict the relative temporal evolution of the 2016/17 wildfire season skillfully compared to observed climatology, though the models underestimate the absolute magnitude of the observed wildfire peak in late January (Figs. 4a,b). In December, levels of modeled and observed FRP are relatively low. In terms of wildfire occurrence, predictions are relatively high compared to observations, and the forecast is less certain (larger ensemble spread), mainly reflecting variability in forecast precipitation.

During January, there is very good agreement between the timing of the increase in observed and modeled mean FRP and wildfire occurrence beginning early in the month. The burned area forecasts also predict the late January anomaly but tend to have a greater temporal lag. This is likely in part due to variations in temporal aggregation used between the training and validation datasets ("Satellite fire characteristics data" section). Though model timing shows general good agreement with observations, observed fire occurrence, mean FRP, and burned area are larger than model predictions by several orders of magnitude during the peak period.

In late January and into February, the forecast models exhibit a peak slightly after the satelliteobserved peak. Mean FRP remains relatively high throughout February, while wildfire occurrence decreases sharply after 27 January, approximately four days after the corresponding observed peak and decrease. This is likely because the most combustible fuel had already been consumed, so there was relatively little left to burn even though conditions remained conducive for wildfires. The models use weather data as dynamic input and have no information about changing fuel and vegetation characteristics, so modeled wildfire characteristics reflect the continuing above-average temperatures and longerterm precipitation deficit (Fig. 4d). Wildfire control efforts by emergency responders and the increased awareness of the public also likely influenced wildfire characteristics, independent of weather variables.

\section{COMMUNICATING WILDFIRE FORE-}

CASTS: STEP 3. The wildfire warnings are based on the probabilistic wildfire forecasts. The probability of a given event is determined from the fraction of ensemble members that predict an event. An event occurs when the predicted wildfire metric exceeds a given threshold. The wildfire warning system generates warnings from a global ensemble prediction system and uses low, medium, and high thresholds for each parameter forecast (fire count, mean fire radiative power, and burned area) to assign the severity of the event. In this prototype, each wildfire zone is considered separately, and risk thresholds vary geographically, taking account of varying levels of severity of each parameter in different parts of Chile. For example, a small number of wildfires may have little impact in zone 15 , where there is a small population and no native forests, but have a much higher impact in zone 2 , which includes Santiago, where the population density is much higher. The warning system is designed to be flexible so that risk thresholds can be defined using a variety of approaches, for example, based on expert consensus or objective cost functions (Economou et al. 2016).

Multifaceted warnings. How best to communicate uncertainty information in a way that people can readily understand is an active topic of research. There have been several research studies on public understanding of uncertainties and probabilistic forecasts, showing evidence that decision-making with uncertainty information is improved (Joslyn and Savelli 2010; Mulder et al. 2017) but also that people may misunderstand probability forecasts (Griffith and Leonard 1997; Joslyn and Nichols 2009).

To reduce any potential misunderstandings, we make use of a multifaceted approach to provide the large range of decision-makers with an alert containing the right level of information they need to implement action plans. This approach is based on the Met Office National Severe Weather Warning System (NSWWS; Neal et al. 2014). Warnings are presented in a variety of ways:

1) Wildfire warning maps showing a color-coded risk warning in each region: Four warning colors (green, yellow, amber, or red) are based on the probability of a particular wildfire event occurring and the severity of the predicted event if it does occur. Maps showing the colored warning in each zone are designed to give forecasters a quick overview of wildfire risk [Fig. 1, step 3 (left)].

2) Wildfire warning levels: A numeric value showing the highest risk warning in each zone. The 
numeric warnings are designed to allow forecasters to distinguish between high-probability-lowseverity events and low-probability-high-severity events [Fig. 1, step 3 (middle)].

3) Wildfire warning probability density functions (PDFs): The full probability distribution of severity in each zone. These warnings are designed to allow forecasters to estimate whether warnings are generated by outliers or unpredictable synoptic situations [Fig. 1, step 3 (right)].

In the colored wildfire warning maps, green indicates "no action necessary," yellow indicates "be aware" that action may be necessary, amber indicates "be prepared" to take action, and red indicates "take action." The colors reflect a combination of probability and severity. For example, yellow could mean either a high probability of a low-severity event forecast or a very low probability of a high-severity event forecast. If the probability of a high-severity event is increased or decreased as the forecast is updated, the warning level may be increased from yellow to amber or red (or vice versa). The appropriate action depends on the decision-maker. Example actions include wildfire prevention by forest managers such as creating fire breaks, organizing the logistics of firefighters for wildfire suppression, issuing advice and preparing evacuation procedures by government agencies, or rescheduling of outdoor activities by the general public.

It should be noted, however, that, while the color system is simple, the association between color and risk can be misunderstood. For example, red is often associated with burning structures or vegetation, and green associated with unburned vegetation. Thus, it is possible that yellow and green alerts may be interpreted as low wildfire severity rather than low levels of risk. Similar interpretations were found by Tang and Rundblad (2015) for temperature warnings.

Tang and Rundblad (2015) found that the use of a number-based tiered warning system was an effective way of representing graduations of risk. Therefore, in addition to the colored wildfire warning maps, a wildfire warning level indicating the highest risk warning in each region is used [boldface in Fig. 1, step 3 (middle)]. Here, severity takes priority over probability, giving emphasis where appropriate to low-probability-high-severity events. A numeric value between 1 and 16 (although in practice numbers 1-3 cannot be issued) is less likely to be associated with burning vegetation and more likely to be interpreted as an alert level. The numeric warnings also allow forecasters to distinguish, for example, between a yellow warning that represents either a high $(50 \%-75 \%)$ probability of a low-severity event (numeric value 7 , Table 2 ) or a very low $(0 \%-25 \%)$ probability of a high-severity event (numeric value 11; e.g., Fig. 1, zone 12, and Table 2).

Finally, for the most sophisticated users, the full probability density function can be used. This shows the number of ensemble members that contribute to each severity category, thus giving a more detailed representation of the uncertainty in the forecast. For example, narrow peaked distributions demonstrate a high degree of confidence in the severity forecast (e.g., Fig. 1, zone 11), whereas flat distributions indicate

TABLE 2. Wildfire risk warning levels.

\begin{tabular}{|clll|}
\hline Risk level & Risk color & \multicolumn{1}{c|}{ Likelihood and severity of event } & Action \\
\hline I-4 & Green & Very low-severity event predicted & No action necessary \\
\hline 5 & Green & Very low probability $(<25 \%)$ of low-severity event & No action necessary \\
\hline 6 & Green & Low probability $(25 \%-50 \%)$ of low-severity event & Be aware \\
\hline 7 & Yellow & Moderate probability $(50 \%-75 \%)$ of low-severity event & Be aware \\
\hline 8 & Yellow & High probability $(>75 \%)$ of low-severity event & Be aware \\
\hline 9 & Yellow & Very low probability $(<25 \%)$ of moderate-severity event & Be aware \\
\hline 10 & Yellow & Low probability $(25 \%-50 \%)$ of moderate-severity event & Be aware \\
\hline 11 & Yellow & Very low probability $(<25 \%)$ of high-severity event & Action may be necessary \\
\hline 12 & Amber & Moderate probability $(50 \%-75 \%)$ of moderate-severity & Action may be necessary \\
\hline 13 & Amber & High probability $(>75 \%)$ of moderate-severity event & Action may be necessary \\
\hline 14 & Amber & Low probability $(25 \%-50 \%)$ of high-severity event & Action may be necessary \\
\hline 15 & Amber & Moderate probability $(50 \%-75 \%)$ of high-severity event & Take action \\
\hline 16 & Red & High probability $(>75 \%)$ of high-severity event &
\end{tabular}


large uncertainty (e.g., Fig. 1, zone 12). Ensemble predictions with single-member outliers can also be visualized, prompting the forecaster to investigate this forecast in more detail.

Chilean workshop. We tested the probabilistic warning system during a 2-day workshop hosted at the DMC in Santiago on 6-7 April 2017. The workshop was attended by 30 researchers. The workshop objectives were to

1) exchange knowledge about Chilean wildfires,

2) discuss the current wildfire warning systems and methods of communication used in Chile, and

3) investigate the most effective ways of interpreting and communicating probabilistic wildfire warnings.

The workshop began with scientific presentations about the development of ensemble weather prediction systems in Chile; remotely sensed data products for wildfire studies; the historical context of wildfires in Chile; and a summary of the 2016/17 wildfire season and its ecological, social, and economic impacts. The development of the prototype wildfire model was then presented, followed by an explanation of the probabilistic risk matrix communication tool and a hands-on workshop using the prototype tool. During the day, there were group discussions about the current wildfire prediction systems used in Chile, the different communication methods used, and understanding of the probabilistic warnings. The discussion highlighted the fact that there are currently several warning systems for Chile that are communicated in a variety of ways:

- DMC issues daily map- and text-based meteorological forecasts of temperature, relative humidity, and wind speed, which are easy to interpret but require extensive user knowledge about the relationship between meteorological conditions and wildfires to make decisions.

- The Brazilian National Institute for Space Research (INPE) issues a daily deterministic fire risk forecast for the whole of South America, but there was confusion about whether this was a forecast for a high number of fires, intensity of fires, large fires, or a combination of all three. There was also concern that the model was trained on Brazilian land cover and wildfire data rather than Chilean data. A group of researchers had also initiated preliminary work to apply the Canadian FWI system as the foundation for a fire early-warning system in Chile, but the status of this work was unknown.

- Weekly warnings are issued by the Oficina Nacional de Emergencia del Ministerio del Interior y Sequridad Publica (ONEMI). These are issued as text-based reports, and it was thought that the public did not respond to this kind of communication. DMC had also experimented with disseminating text-based warnings via social networking (specifically Twitter), but the uptake was low. Generally, it was decided that warning systems using maps and color-coded graphics could be more successful at getting the public to take appropriate action and that a mobile phone application may be more effective when attempting to warn the public.

- One interesting example given of an effective warning system in Chile was the tidal wave warnings issued by the navy. These are broadcast on television and radio, and the general sense was that this was effective because the public had been trained in how to respond to such warnings.

- Understanding of how the wildfire warnings were calculated was high, although some participants were confused at the decision to issue the highest risk warning rather than the highest probability warning. The workshop participants were enthusiastic about the wildfire warning maps and wildfire warning levels but thought that the wildfire warning PDFs would only be used by a small group of specialized users.

In summary, we concluded that a transparent wildfire warning system based on Chilean vegetation and Chilean wildfire data is needed in Chile. The discussion also confirmed that wildfire warning maps showing color-coded risk would be appropriate for communication with the public but that they should be issued with information on what actions should be taken following different warnings.

DISCUSSION. In this paper, we describe the design of an end-to-end prototype probabilistic daily wildfire warning system for Chile. The warning system has been shown to perform well for the 2016/17 Chilean wildfire season compared to climatology; however, several potential improvements must be considered before such a system could become operational. These are discussed in this section.

The approach described in this paper makes full use of global Earth observation data, both fire characteristics and vegetation measurements, to construct 15 regional models for Chile. One advantage of this 
satellite-driven approach is that predictions can be directly compared to satellite observations. Outputs from other indices (such as the Canadian FWI) represent quantities (e.g., rate of fire spread, available fuel, frontal fire intensity) that are less straightforward to compare against satellite measurements. The availability of reasonable-length historical MODIS fire data (16 years to date) makes this a feasible approach for most regions worldwide. An opportunity to apply this methodology at the global scale would rely on the use of different EO sensors for fire applications. The MODIS sensors on board Terra and Aqua have a life expectancy of 2020 and 2025, respectively; however, new sensors with dedicated fire channels could be used to provide additional and improved fire observations, for example, the Sea and Land Surface Temperature Radiometer (SLSTR) instrument on board Sentinel-3A and the Advanced Baseline Imager (ABI) instrument on the GOES-16 and Japanese Himawari-8 geostationary satellites. Together with the aforementioned VIIRS instrument, it would be possible to use fire identifications and associated FRP from different sensors to integrate them and derive a dataset that could be used to train the model and provide a better understanding of the fire diurnal cycle and the impact of small fires.

It should be noted that while the models performed well at predicting the temporal evolution of wildfire occurrence and relative magnitude of mean FRP for the 2016/17 Chilean wildfire season, the absolute magnitudes of wildfire metrics were underestimated by the model, particularly during the late January wildfire peak. This is partly due to the unprecedented nature of the 2016/17 season compared to the data in the 16-yr model training datasets.

The models were able to predict the increase in mean FRP that occurred during 2016/17 Chilean wildfire season in a manner consistent with the satellite observations. However, they were unable to capture the reduction in mean FRP occurring in the later part of the season. This likely occurred because, even though conditions remained favorable for wildfires, the combustible fuel was all used up. One potential improvement to the wildfire model forecasts therefore would be to use a daily NDVI anomaly rather than a climatological mean daily NDVI. This would allow the reduction in NDVI due to previous burning to be accounted for.

In terms of wildfire occurrence, the model predictions were generally more skillful in predicting burned area and mean FRP than wildfire occurrence. This could potentially occur because wildfire occurrence has a larger anthropogenic component. Since most wildfires in Chile are started because of accidental ignition by humans (Ubeda and Sarricolea 2016), one potential improvement to the wildfire occurrence models could be to introduce additional anthropogenic variables such as distance to roads, road density, population density, or day-of-week dependence. When modeling wildfires in other regions, where a larger amount of natural ignition occurs, it may also be important to include additional ignition variables such as lightning (Abatzoglou et al. 2016).

In this paper, we have not assessed how closely the forecast probabilities of wildfire events correspond to the actual chance of observing the event, as currently we are limited by the amount of data available. However, once more years of forecast and fire occurrence data become available, quantitative evaluation of the probabilistic forecasts, such as performed by Preisler et al. (2016), will be possible.

In this prototype system, the wildfire warnings are communicated on a regional basis. Chile was split into 15 zones based on an earlier wildfire severity index model developed for Chile by Julio (1990). These 15 geographic zones loosely distinguish between vegetation types in central Chile. These zones are somewhat arbitrary, and their delineation is likely outdated (e.g., from land-use and land-cover changes). It is therefore advisable to revisit the zones and improve the zone classifications. In theory, it is possible to create regions at the resolution of the meteorological input data $\left(0.5^{\circ}\right.$ latitude and longitude) if required. Furthermore, when calculating the FDD, a baseline air temperature was introduced based on minimizing the mean absolute error in zone 8 (zone with the highest occurrence of fires). This FDD baseline was applied to all zones. An improvement to the models could be made if a specific FDD baseline was created for each zone.

The severity thresholds used to create the risk matrix were based on the climatological fire characteristics for each region; that is, the low-, medium-, and high-severity thresholds were set to $25 \%, 50 \%$, and $75 \%$ of the maximum value observed in the region over the last 16 years. This hazard-based approach does not take into account the impact of the hazard in each region. Recent examples of prediction systems that take an impact-based approach include Molina et al. (2017), Castillo et al. (2017), GómezGonzález et al. (2017), and Boer et al. (2017). One way to incorporate the impact could be to weight the hazard by the related economic damage in each region (e.g., caused by the potential loss of timber for a given hazard value-provided the data are available) or to weight the hazard by the threat to human life using 
the population density in the region. Similarly, the likelihood thresholds were split equally (i.e., set to $25 \%, 50 \%$, and $75 \%$ ). Ideally, these impact and likelihood thresholds would be adjusted to optimize the number and severity of warnings in each region over a training period.

CONCLUSIONS. In this paper, we describe the design of a novel prototype probabilistic daily wildfire warning system for Chile. This system synthesizes state-of-the-art ensemble weather forecasts with satellite-observed fire and vegetation data to predict, visualize, and communicate likelihood of wildfire risk. This probabilistic approach is advantageous because uncertainties are quantified so that users can make more informed decisions.

The design of the wildfire warning system has been split into three steps: step 1: building the wildfire models; step 2: producing the wildfire forecasts; and step 3: communicating the wildfire warnings. Each of these steps is equally important in order to produce useful forecasts. The system is designed to be flexible so that it can be applied to other probabilistic natural hazard forecasts in any geographic region.

In step 1, we built statistical models for 15 zones in central Chile using historical satellite measurements of vegetation and wildfires plus historical numerical weather prediction data. The models were built to predict three satellite-observed variables; fire intensity, burned area, and number of fires up to six days in advance.

In step 2, we attempted to forecast the severe 2016/17 Chilean wildfire season. Evaluating the 3-day forecasts against independent satellite datasets, we conclude that the models show good skill. They predicted the temporal evolution of the three variables better than climatology but underestimated their magnitude. This is likely due to the extreme nature of this season, which was the highest fire season in Chile on record 5 times the second highest $(2014 / 15)$ in terms of burned area].

In step 3, we developed a multifaceted approach for communicating the probabilistic forecasts to a variety of end users based on the Met Office National Severe Weather Warning System (NSWWS; Neal et al. 2014). This approach was tested at a workshop in Chile. We concluded that the risk matrix approach is appropriate for communicating wildfire warnings; however, more work is needed to understand the severity thresholds appropriate for different regions in Chile. In addition, the method of dissemination requires some thought, particularly when warning the public. It is important to include the actions that should be taken when different warnings are issued.

ACKNOWLEDGMENTS. We thank the Dirección Meteorológica de Chile for hosting our 2-day workshop at their beautiful facilities in Santiago. We are also grateful to all of the workshop participants who shared their time and extensive expertise at the workshop by presenting work, participating in the hands-on exercises, and engaging in discussions about the current and potential future of wildfire prediction in South America. We would also like to thank Alfredo Mascareno at CONAF for useful discussions of this work. We are grateful to funding from the Newton Fund managed by STFC. Gracias y thanks.

\section{REFERENCES}

Abatzoglou, J. T., C. A. Kolden, J. K. Balch, and B. A. Bradley, 2016: Controls on interannual variability in lightning-caused fire activity in the western US. Environ. Res. Lett., 11, 045005, https://doi .org/10.1088/1748-9326/11/4/045005.

Aldunce, P., D. Araya, R. Sapiain, I. Ramos, G. Lillo, A. Urquiza, and R. Garreaud, 2017: Local perception of drought impacts in a changing climate: The megadrought in central Chile. Sustainability, 9, 2053, https://doi.org/10.3390/su9112053.

Boer, M. M., R. H. Nolan, V. Resco de Dios, H. Clarke, O. F. Price, and R. A. Bradstock, 2017: Changing weather extremes call for early warning of potential for catastrophic fire. Earth's Future, 5, 1196-1202, https://doi.org/10.1002/2017EF000657.

Bougeault, P., and Coauthors, 2010: The THORPEX Interactive Grand Global Ensemble. Bull. Amer. Meteor. Soc., 91, 1059-1072, https://doi.org/10.1175 /2010BAMS2853.1.

Castillo, M. E., J. R. Molina, F. R. y Silva, P. GarcíaChevesich, and R. Garfias, 2017: A system to evaluate fire impacts from simulated fire behavior in Mediterranean areas of central Chile. Sci. Total Environ., 579, 1410-1418, https://doi.org/10.1016/j .scitotenv.2016.11.139.

Chu, P.-S., W. Yan, and F. Fujioka, 2002: Fire-climate relationships and long-lead seasonal wildfire prediction for Hawaii. Int. J. Wildland Fire, 11, 25-31, https://doi.org/10.1071/WF01040.

Dowdy, A. J., G. A. Mills, K. Finkele, and W. de Groot, 2009: Australian fire weather as represented by the McArthur Forest Fire Danger Index and the Canadian Forest Fire Weather Index. Centre for Australian Weather and Climate Research Tech. Rep. 10, 91 pp. 
Economou, T., D. Stephenson, J. Rougier, R. Neal, and K. Mylne, 2016: On the use of Bayesian decision theory for issuing natural hazard warnings. Proc. Roy. Soc., 472A, 20160295, https://doi.org/10.1098 /rspa.2016.0295.

Field, R., and Coauthors, 2015: Development of a global fire weather database. Nat. Hazards Earth Syst. Sci., 15, 1407-1423, https://doi.org/10.5194 /nhess-15-1407-2015.

Friedl, M. A., D. Sulla-Menashe, B. Tan, A. Schneider, N. Ramankutty, A. Sibley, and X. Huang, 2010: MODIS collection 5 global land cover: Algorithm refinements and characterization of new datasets. Remote Sens. Environ., 114, 168-182, https://doi.org/10.1016/j. rse.2009.08.016.

Giglio, L., T. Loboda, D. P. Roy, B. Quayle, and C. O. Justice, 2009: An active-fire based burned area mapping algorithm for the MODIS sensor. Remote Sens. Environ., 113, 408-420, https://doi.org/10.1016/j .rse.2008.10.006.

—, W. Schroeder, and C. O. Justice, 2016: The collection 6 MODIS active fire detection algorithm and fire products. Remote Sens. Environ., 178, 31-41, https:// doi.org/10.1016/j.rse.2016.02.054.

Gómez-González, S., F. Ojeda, and P. M. Fernandes, 2017: Portugal and Chile: Longing for sustainable forestry while rising from the ashes. Environ. Sci. Policy, 81, 104-107, https://doi.org/10.1016/j .envsci.2017.11.006.

González, M. E., T. T. Veblen, and J. S. Sibold, 2005: Fire history of Araucaria-Nothofagus forests in Villarrica National Park, Chile. J. Biogeogr., 32, 1187-1202, https://doi.org/10.1111/j.1365-2699.2005.01262.x.

Griffith, L. J., and S. D. Leonard, 1997: Association of colors with warning signal words. Int. J. Ind. Ergon., 20, 317-325, https://doi.org/10.1016/S0169 -8141(96)00062-5.

Holz, A., T. Kitzberger, J. Paritsis, and T. T. Veblen, 2012: Ecological and climatic controls of modern wildfire activity patterns across southwestern South America. Ecosphere, 3, 103, https://doi.org/10.1890 /ES12-00234.1.

Joslyn, S. L., and R. M. Nichols, 2009: Probability or frequency? Expressing forecast uncertainty in public weather forecasts. Meteor. Appl., 16, 309-314, https:// doi.org/10.1002/met.121.

— , and S. Savelli, 2010: Communicating forecast uncertainty: Public perception of weather forecast uncertainty. Meteor. Appl., 17, 180-195, https://doi .org/10.1002/met.190.

Julio, G., 1990: Diseño de índices de riesgo de incendios forestales para Chile. Bosque, 11, 59-72, https://doi .org/10.4206/bosque.1990.v11n2-06.
Klein Goldewijk, K., A. Beusen, J. Doelman, and E. Stehfest, 2017: Anthropogenic land use estimates for the Holocene-HYDE 3.2. Earth Syst. Sci. Data, 9, 927-953, https://doi.org/10.5194/essd-9-927 $-2017$.

Masato, G., and Coauthors, 2015: Improving the health forecasting alert system for cold weather and heat-waves in England: A proof-of-concept using temperature-mortality relationships. PLOS ONE, 10, e0137804, https://doi.org/10.1371/journal .pone. 0137804 .

Molina, J. R., R. Moreno, M. Castillo, and F. R. y Silva, 2017: Economic susceptibility of fire-prone landscapes in natural protected areas of the southern Andean range. Sci. Total Environ., 619-620, 1557-1565, https://doi.org/10.1016/j.scitotenv.2017.11 .233 .

Mulder, K. J., M. Lickiss, N. Harvey, A. Black, A. Charlton-Perez, H. Dacre, and R. McCloy, 2017: Visualizing volcanic ash forecasts: Scientist and stakeholder decisions using different graphical representations and conflicting forecasts. Wea. Climate Soc., 9, 333-348, https://doi.org/10.1175 /WCAS-D-16-0062.1.

Neal, R. A., P. Boyle, N. Grahame, K. Mylne, and M. Sharpe, 2014: Ensemble based first guess support towards a risk-based severe weather warning service. Meteor. Appl., 21, 563-577, https://doi.org/10.1002 /met.1377.

Neale, T., and J. K. Weir, 2015: Navigating scientific uncertainty in wildfire and flood risk mitigation: A qualitative review. Int. J. Disaster Risk Reduct., 13, 255-265, https://doi.org/10.1016/j.ijdrr.2015.06 .010 .

Oliva, P., and W. Schroeder, 2015: Assessment of VIIRS $375 \mathrm{~m}$ active fire detection product for direct burned area mapping. Remote Sens. Environ., 160, 144-155, https://doi.org/10.1016/j.rse.2015.01.010.

Preisler, H. K., K. L. Riley, C. S. Stonesifer, D. E. Calkin, and W. M. Jolly, 2016: Near-term probabilistic forecast of significant wildfire events for the western United States. Int. J. Wildland Fire, 25, 1169-1180, https://doi.org/10.1071/WF16038.

Running, S. W., 2006: Is global warming causing more, larger wildfires? Science, 313, 927-928, https://doi .org/10.1126/science.1130370.

Schroeder, W., P. Oliva, L. Giglio, and I. A. Csiszar, 2014: The New VIIRS $375 \mathrm{~m}$ active fire detection data product: Algorithm description and initial assessment. Remote Sens. Environ., 143, 85-96, https://doi.org/10.1016/j.rse.2013.12.008.

Tang, C., and G. Rundblad, 2015: The potential impact of directionality, colour perceptions and cultural 
associations on disaster messages during heatwaves in the UK. PLOS Curr. Disasters, 7, https://doi.org/10.1371 /currents.dis.775c310222d5829cb29b7a414370ca50.

Taylor, S. W., D. G. Woolford, C. Dean, and D. L. Martell, 2013: Wildfire prediction to inform management: Statistical science challenges. Stat. Sci., 28, 586-615, https://doi.org/10.1214/13-STS451.

Tucker, C. J., 1979: Red and photographic infrared linear combinations for monitoring vegetation. Remote Sens. Environ., 8, 127-150, https://doi .org/10.1016/0034-4257(79)90013-0.
Ubeda, X., and P. Sarricolea, 2016: Wildfires in Chile: A review. Global Planet. Change, 146, 152-161, https:// doi.org/10.1016/j.gloplacha.2016.10.004.

Van Wagner, C., 1987: Development and structure of the Canadian Forest Fire Weather Index system. Canadian Forestry Service Tech. Rep. 35, 37 pp., http://cfs.nrcan.gc.ca/pubwarehouse/pdfs/19927.pdf.

Westerling, A. L., A. Gershunov, T. J. Brown, D. R. Cayan, and M. D. Dettinger, 2003: Climate and wildfire in the western United States. Bull. Amer. Meteor. Soc., 84, 595-604, https://doi.org/10.1175/BAMS-84-5-595.

\section{"A thoughtful analysis of actions that we need to take to reduce the impacts of extreme weather... a must-read for everyone with an interest in the weather and climate." \\ - FRANKLIN W. NUTTER, \\ President, Reinsurance Association of America}

\section{Living on the Real World: How Thinking and Acting Like Meteorologists Will Help Save the Planet}

WILLAM н. НООКЕ

Meteorologists sift through a deluge of information to make predictions every day. Instead of being overwhelmed by the data and possibilities, they focus on small bits of information while using frequent collaboration to make decisions. With climate change a reality, William H. Hooke suggests we look to the way meteorologists operate as a model for how we can solve the twenty-first century's most urgent environmental problems. 